\title{
RECOVERY OF THE SEISMOGRAM AND GENERATION OF THE SEMI- SYNTHETIC ACCELEROGRAM FOR BAHÍA OF CARAQUEZ EARTHQUAKE (MS = 7.2)
}

RECUPERACIÓN DEL SISMOGRAMA Y GENERACIÓN
DEL ACELEROGRAMA SEMI-SINTÉTICO PARA
EL TERREMOTO BAHÍA DE CARAQUEZ (MS = 7.2)

\section{MARCELO MONCAYO THEURER}

Universidad de Guayaquil. marcelo.moncayot@ug.edu.ec

RESUMEN

El terremoto de Bahía de Caráquez ocurrió en agosto de 1998. Este es el evento sísmico más importante en Ecuador en los últimos años. Los sismogramas registrados fueron cortados en los puntos de pico porque las aceleraciones superaron el valor máximo que se estableció para el sensor. Se propone el Método de Intersección Reducida para reconstruir la parte cortada de los sismogramas. El método se prueba con el terremoto de Bahía de Caráquez, cortando intencionalmente sus acelerogramas para luego, reconstruirlos. Los resultados se filtran para eliminar el ruido ambiental y se construyen espectros elásticos para comparar los resultados.

PALABRAS CLAVE: sismograma, Método de Intersección Reducida, terremoto de Bahía de Caráquez.
The Bahía de Caráquez earthquake occurred on August of 1998. This is the most important seismic event in Ecuador in recent years. The seismograms recorded were cut at the peak points because the accelerations overcame the maximum value that was settled for the sensor.

The Reduced Intersection Method is proposed to reconstruct the cut portion of the seismograms. The method is tested with of Bahía de Caráquez earthquake, cutting intentionally its accelerograms for afterward, reconstructing them. The results are filtered to eliminate ambiental noise and elastic spectras are constructed to compare the results.

KEYWORDS: Seismogram, Reduced Intersection Method, Bahía de Caráquez earthquake. 


\section{INTRODUCCIÓN}

On August 4th of 1998 a big earthquake of MS = 7.2 with epicenter located at latitude $0.593 \mathrm{~S}$ and longitude $80.83 \mathrm{~W}$ (USCS catalogue), struck the coastal city of "Bahía de Caráquez" in Ecuador. This city is an important tourist site, so that tall buildings and modern tourist facilities have been constructed in recent years.

The structural damage was not severe, although one modern six-floor apartment building totally collapsed ${ }^{1}$; on the other hand, the damage observed in masonry elements was very large. That is why these strong motion data are valuable for researchers in Ecuador.

The analyzed data are from stations located at Manta, Salinas and Guayaquil, but these seismograms were cut by equipment limitations. This paper uses the "reduced intersection method" to recover the cut portion.

\section{STATIONS AND STRONG MOTION DATA}

The seismograms used in this analysis are from; the station of Manta, $60 \mathrm{~km}$ from the epicenter; the station of Guayaquil and Salinas, $150 \mathrm{~km}$ from the epicenter. Each seismogram has; channel 1 which is vertically oriented; channel 2 which is North - South and channel 3 which is East - West oriented.

The entity in charge of the stations informed that each station has a seismogram IDS-3602A that records with $\Delta \mathrm{T}=0.004 \mathrm{~s}$. The sensor is a triaxial geophon with an equivalent scale of $0.015 \mathrm{mg}$ ( $0.5 \mathrm{~g}, 32767$ counts) (4). The level of accelerations obtained (table 1) are strongly depending on this value, but this equivalent scale has generated some discrepancies, for that reason the results are presented normalized to 1 and the accelerations presented separately. In spite of this discussion the process of reconstruction by the reduced intersection method is totally valid and is giving good results. According to this equivalent scale, the maximum level of the geophon was settled at $0.5 \mathrm{~g}$, the accelerograms recorded in most of the stations overcame this value and the peak values of the seismograms were cut (figure 1).

Foreign Invited Researcher, University of Tokyo, Institute of Industrial Science, Steel Structures Laboratory, Postal Code 153-8505 Tokyo - Japan JICA Participant, Building Research Institute, Earthquake Engineering Course 1999-2000 Researcher, Escuela Superior Politecnica del Litoral, Facultad en Ciencias de la Tierra E-mail: marcelo_moncayo_theurer@yahoo.com

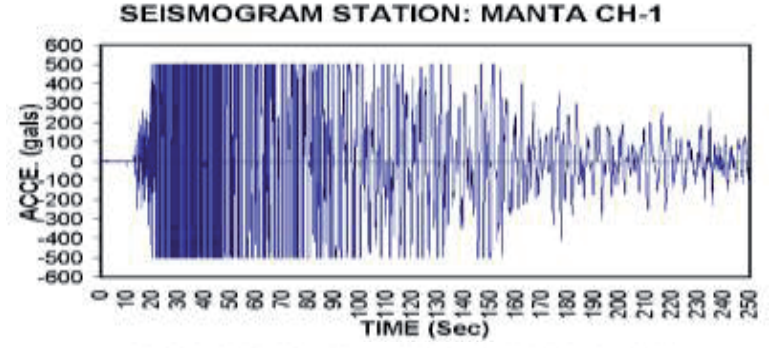

SEISMOGRAM STATION: SALINAS CH-2
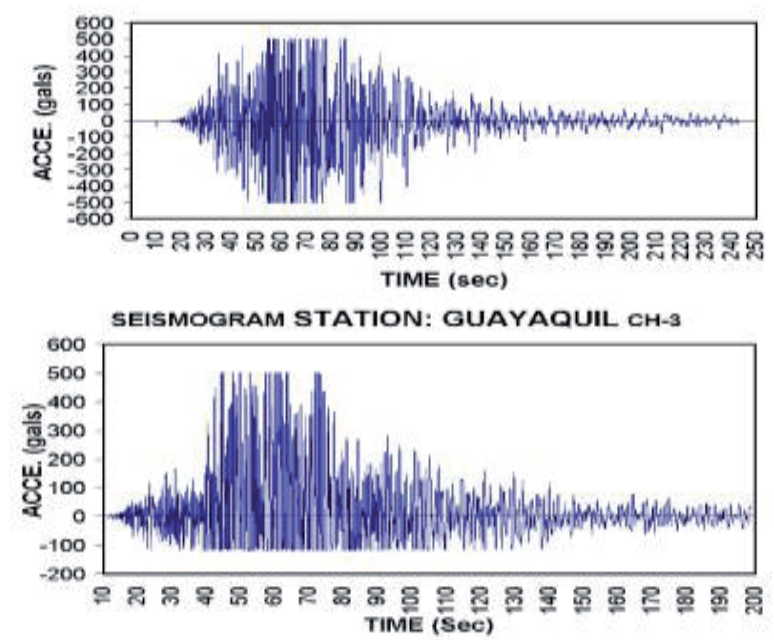

Figure 1. Original seismograms.

REDUCED INTERSECTION METHOD

A random process is a family of functions $Y(t, w)$ that depends on two arguments, the time $t$ and a random event which could be symbolized by $\mathrm{w}$. If $\mathrm{w}=\mathrm{w} 0$, the random event is fixed so that $\mathrm{Y}(\mathrm{t}, \mathrm{w} 0)$ is a random function depending on time and is the product of a specific random event. This type of fixed random function could be called $\mathrm{Y}(\mathrm{t})$ (3) and have similar characteristics than an accelerogram.

In figure. 2 there is a semi-cycle taken from a random wave, this semi-cycle is cut at level $\mathrm{L}$. To reconstruct the semi-cycle, it is necessary to draw a line A with positive pendant, parallel to the known tendency and that contains the point $\mathrm{A} 1$ and draw a line $\mathrm{B}$ with negative pendant parallel to the known tendency of the function and that contains the point B1. An estimation of the cut peak point Pc is the intersection between line A and line $\mathrm{B}$. The calculated point $\mathrm{Pc}$ is an overestimation of the real point Pr (figure 2) for that reason the height of Pc should be reduced to obtain the real value. The reduction was tested with several relations and the best results were obtained with the Eq. 1, which express a variation of the reduction value depending on the period of the cycle analyzed: 


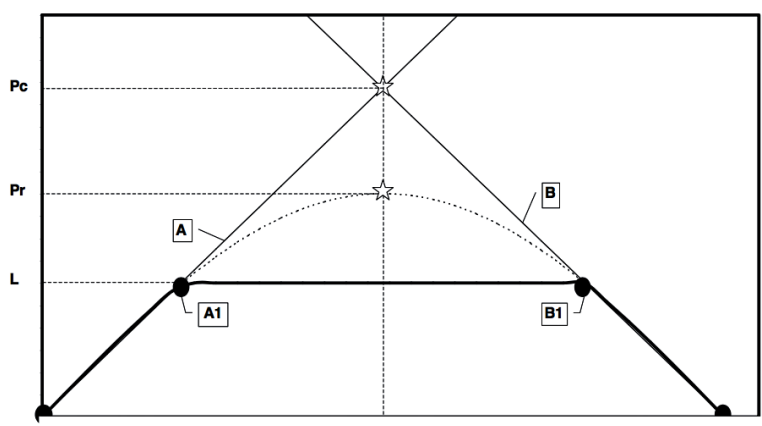

Figure 2. Intersection method.

$$
M=K\left(\frac{T_{N}^{2}+4}{T_{N}^{2}}\right)
$$

Where $\mathrm{M}$ is the reduction value, $\mathrm{TN}$ is the natural period of the complete cycle. The value of the constant $\mathrm{K}$ depends on the level in which the cycle was cut and on the content of frequency of the whole wave.

Finally the reduced estimation is calculated by:

$$
\mathrm{P}_{r}=L+\frac{P_{c}}{M}
$$

\section{APPLICATION OF THE REDUCED INTERSECTION METHOD REDUCED INTERSECTION METHOD APPLIED TO KOBE}

EARTHQUAKE

The accelerograms of Kobe earthquake were intentionally cut, at 100 gals and 30 gals and afterwards reconstructed using $\mathrm{K}=0.27$ and $\mathrm{K}=0.20$ respectively.

The figure 3 shows the channel 2 of Kobe earthquake, original and reconstructed by the reduced intersection method. The shape of the reconstructed accelerogram is a good approximation of the original.

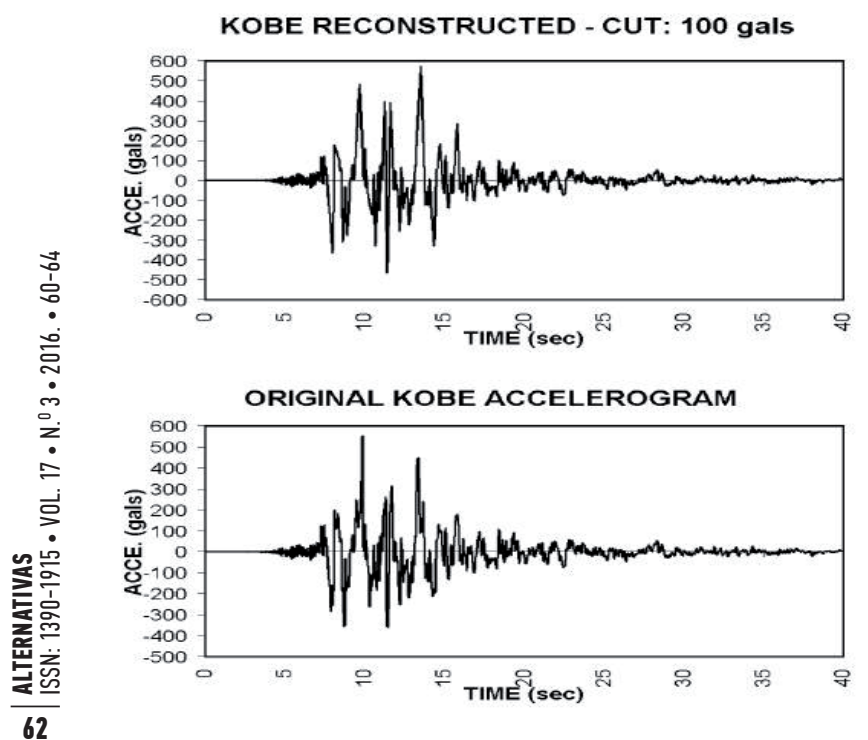

Figure 3. Kobe Earthquake Reconstructed after cutting at 100 gals.

The fourier spectra and elastic spectra of the original and cut accelerograms are compared in figure 4. The spectra of Kobe earthquake, cut at 100 gals (17\% of the maximum peak point), have a very good fitting in terms of contents of frequency and amplitude. The amplitude is 15\% more than the original accelerogram, this give a higher safety margin for the design purposes.

The spectra of the accelerogram cut at 30 gals ( $5 \%$ of the peak point), shows similar amplitudes than the former case but the region of short periods is a little bit shifted. This difference exists because to cut the accelerogram at $5 \%$ of the peak point, is an extreme case and a lot information is lost.
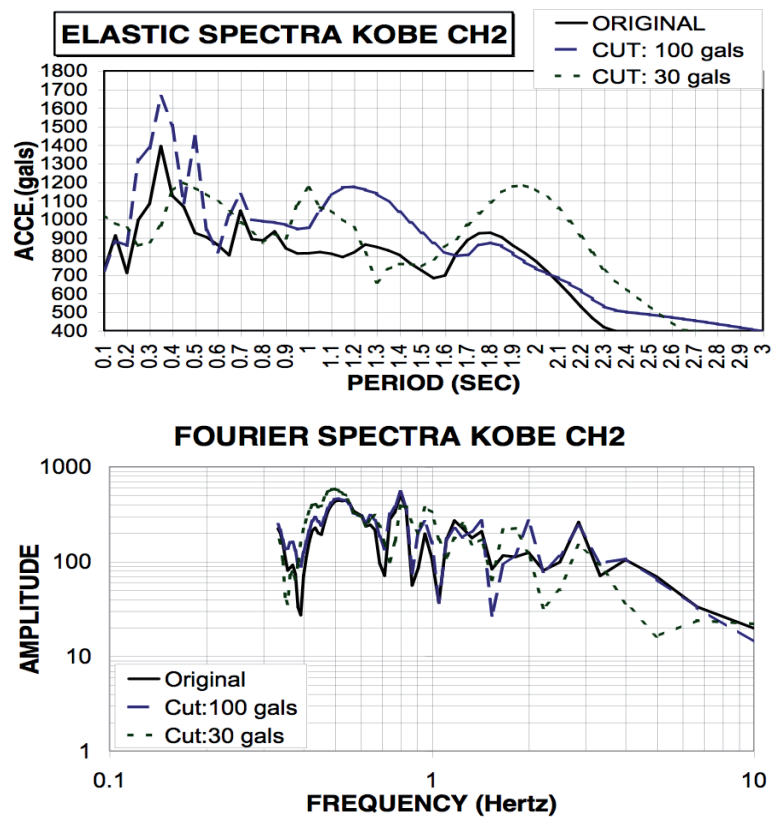

Figure 4. Comparison between elastic and fourier spectra for Kobe Earthquake.

FILTERING, SHAPE AND FINAL RESULTS.

The geophons are very sensible sensors for that reason the recorded seismograms are contaminated by ambiental noise. To eliminate the noise a filter of frequencies higher than 10 Hertz was applied to all the waves (3).

Extremely high peak values may appear specially when the semi-cycles (figure 2) have short periods, in this cases is possible to use a shape curve. For this paper the shape curve was barely used although this is a tool that could work very well with this method.

The reduced intersection method was applied for all the stations and channels and the results are shown in figure 5 in terms of normalized acceleration. The maximum accelerations are 
shown in table 1 , this accelerations are strongly depending on the equivalent scale defined as $0.015 \mathrm{mg}(0.5 \mathrm{~g}, 32767$ counts). This scale has generated some discrepancies for that reason the results are presented normalized to the unit, this fact allows the designer to select the most convenient acceleration from his technical point of view. Although the accelerations calculated show a good relation with the equivalent scale proposed from the beginning, this fact show that the method is giving very good results.

\section{TABLE 1. ACCELERATION IN GALS}

\begin{tabular}{|c|c|c|c|c|}
\hline STATION & K & CHANNEL $1 *$ & CHANNEL 2* & CHANNEL $3^{*}$ \\
\hline Salinas & 1 & 700 & 570 & 650 \\
\hline Guayaquil & 1 & 580 & 660 & 690 \\
\hline Manta & 4 & 880 & 1100 & 1300 \\
\hline
\end{tabular}
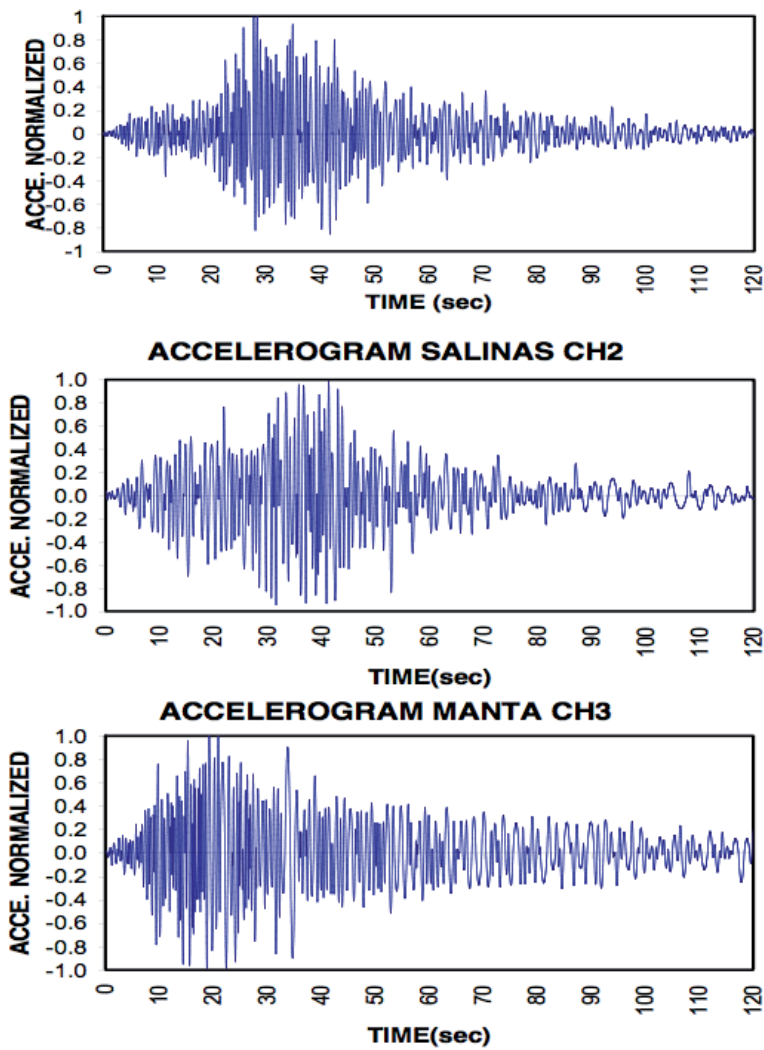

Figure 5. Final accelerograms.

\section{COMPARISON OF THE SPECTRAS AMONG RECONSTRUCTED} AND ORIGINAL ACCELEROGRAMS

The elastic spectra were calculated for the original accelerograms (figure 1) and for the reconstructed ones (figure 5), the results are shown in figure 6 .

In all the stations and channels, the elastic spectras of the reconstructed accelerograms have kept the same content of frequency than the original and they have recovered part of the amplitude lost by the cut of the peak points.
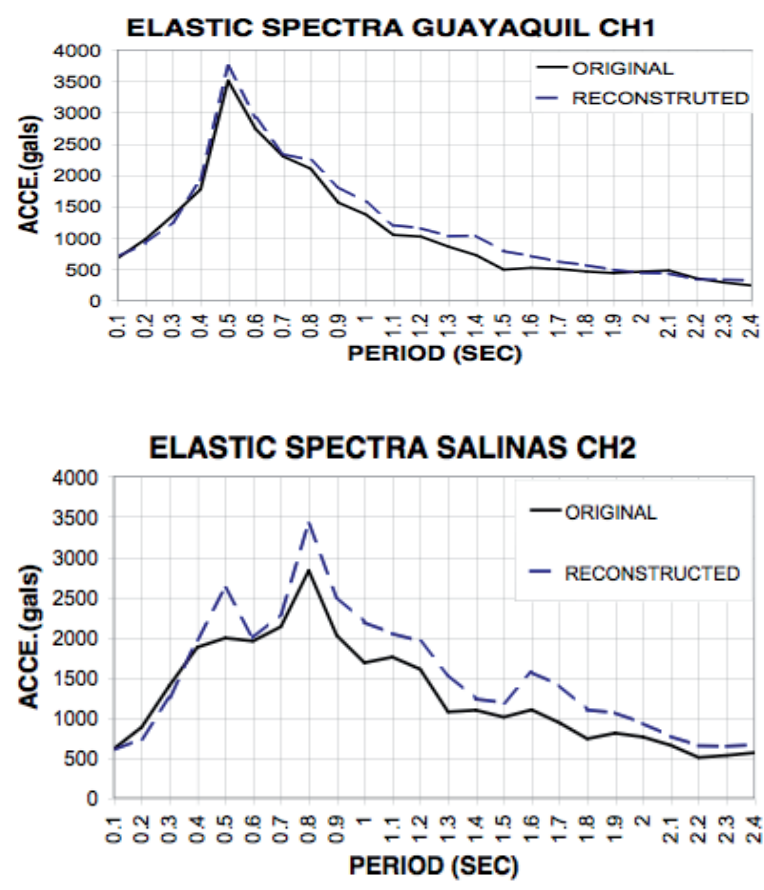

ELASTIC SPECTRA MANTA CH3

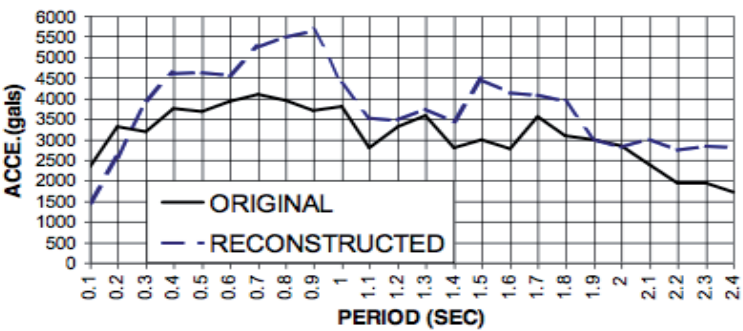

Figure 6. Comparison between original and reconstructed Elastic Spectras.

CONCLUSIONS

The reduced intersection method has been used successfully to recover the peak points for cut waves. The reduction has been tested for several relations and the best result were obtained by the function presented in Eq.1, where the constant $\mathrm{K}$ varies depending on the content of frequency of the soil and on the level in which the accelerograms were cut. The value $\mathrm{TN}$ is the natural period of each cycle.

Eq.1 express an inverse relation between the natural period TN and the reduction value $M$ applied because the method use the pendants of the known tendency to estimate the point Pc (figure 2). In the region of short periods this pendants are high so that the overestimation between Pc and the real peak point Pr is high too. In the region of long periods the overestimation diminish.

To use the original cut accelerograms, in an analysis, could cause sub-estimated effects on 
the structure. The reduced intersection method (R.I.M.) reconstruct the cut part using the information which is contained in the cut accelerograms although the method have a level of uncertainties that increase inversely with the level of cut for that reason these accelerograms have been called semi-synthetic.

To probe the method, the Kobe earthquake was cut at 100 gals and 30 gals. The results are shown in figure 3 and a comparison of the elastic and fourier spectra is in figure 4 . The results after using the reduced intersection method give a very good fitting with the original. This example shows that it is possible to reconstruct, by this method, a cut wave and expect that the results are near the real ones.

The method was applied for the cut seismograms of Bahía de Caráquez earthquake, the results were filtered and they are presented in figure 5. A comparison between the spectras of the original seismogram and the reconstructed accelerograms is shown in figure 6 . The comparison shows that the accelerograms proposed keep the same content of frequency and recover the part of the response lost by the cut, for that reason these accelerograms can be used to reproduce similar effects than the real ones on a structure.
The equivalent scale defined by the institution in charge of the stations has created some discrepancies, for that reason the results are presented normalized. The results of this job can be used inclusive in the case of not to be agreeing with this scale, normalizing the accelerograms to the desire acceleration.

\section{REFERENCES}

1. Fernandez J., Yepez H., "The Bahía de Caráquez, Ecuador, Earthquake of August 4, 1998", Earthquake Engineering Research Institute (EERI), project: learning from earthquakes, web page, 1998.

2. Jenkins, Watts, Spectral analysis and its applications, Holden day, Inc., San Francisco, 1968.

3. Kalman R.E., "New methods in Wiener filtering theory", Proceedings of the first symposium on engineering applications of random function theory and probability, (September 1962): 270388.

4. Bahía de Caráquez records, Universidad Católica de Guayaquil, seismograms, 1998.

5. Moncayo M., "Web Master 2000 vs.1.0", software, Tokyo University, IIS, Ohi Lab, Tokyo,2000. 